$9-1-2021$

\title{
Providing family planning and reproductive health services in factory settings: Lessons from Port Said, Egypt
}

\author{
Nesrine Salama \\ Population Council \\ Maryam Essam \\ Population Council \\ Nahla G. Abdel-Tawab \\ Population Council \\ Elizabeth Tobey \\ Population Council
}

Follow this and additional works at: https://knowledgecommons.popcouncil.org/departments_sbsr-rh How does access to this work benefit you? Let us know!

\section{Recommended Citation}

Salama, Nesrine, Maryam Essam, Nahla G. Abdel-Tawab, and Elizabeth Tobey. 2021. "Providing family planning and reproductive health services in factory settings: Lessons from Port Said, Egypt," Research brief. Washington, DC: Population Council, The Evidence Project. 


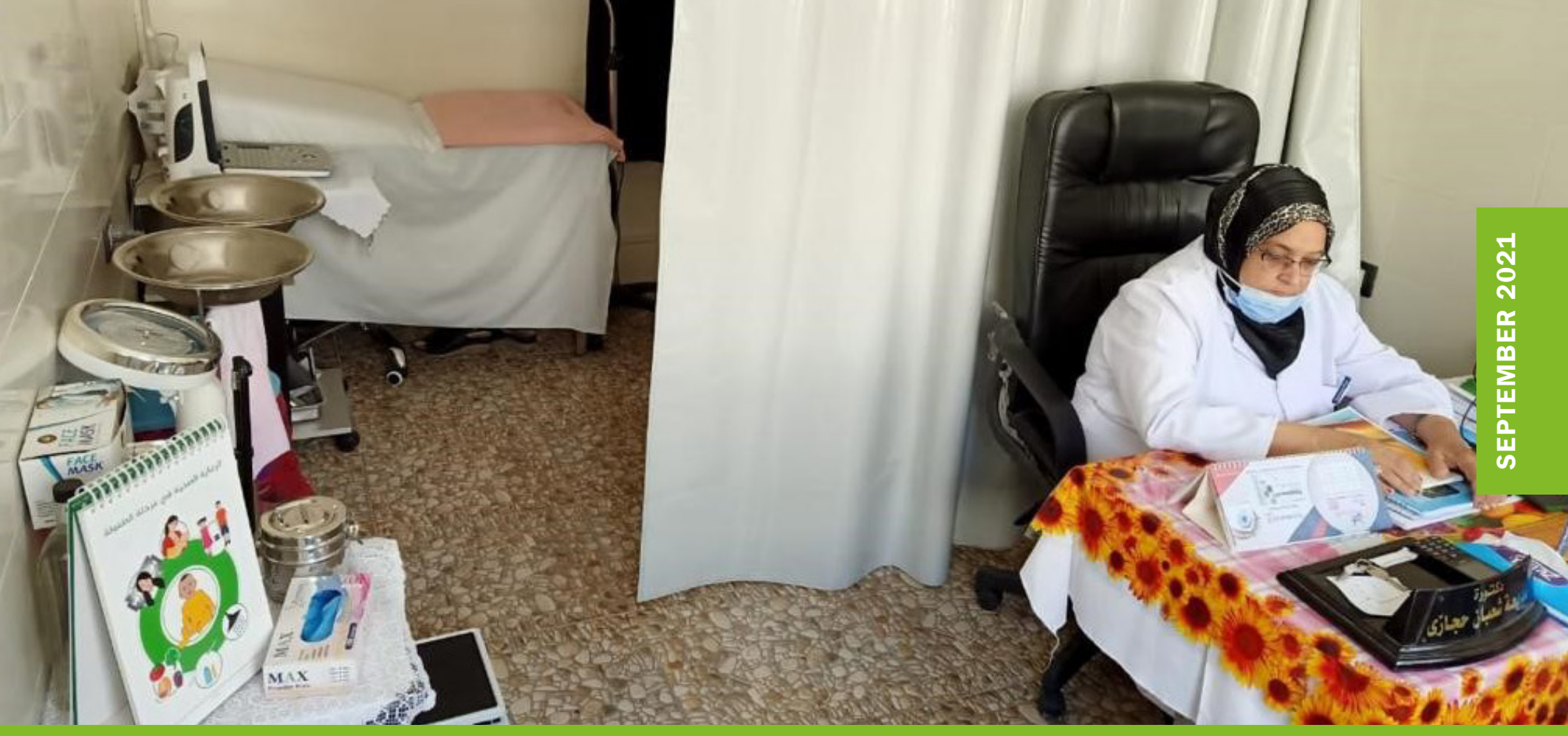

RESEARCH BRIEF

\section{Providing family planning and reproductive health services in factory settings: Lessons from Port Said, Egypt}

\section{BACKGROUND AND RATIONALE}

The number of workers in the industrial sector in Egypt is about 2.6 million, most of them of childbearing age (CAPMAS 2017). Women account for more than $50 \%$ of the workforce in some sectors, like the garment sector. Female workers have health needs related to pregnancy, childbirth, gynecology, and menstrual health while males have informational needs to dispel misconceptions about family planning and reproductive health (FP/RH) (Abdel-Tawab et al. 2020). Given the high proportion of factory workers of reproductive ages, it is crucial that those workers are reached with FP information and FP/RH services, especially because those young men and women will determine the trajectory of future fertility trends in Egypt (Roudi-Fahimi and El Feki 2011).

\section{MODELS FOR OFFERING}

FP SERVICES IN FACTORY SETTINGS

There are several models that could be used for offering FP services in factory settings in Egypt. These include provision of $\mathrm{FP} / \mathrm{RH}$ services through Ministry of Health and Population (MOHP) mobile clinics, offering $\mathrm{FP} / \mathrm{RH}$ counseling by factory nurses and referral to nearby facilities, and offering $\mathrm{FP} / \mathrm{RH}$ services in a factory clinic. The benefits and challenges associated with each of these models are described in the next three sections. 


\section{PROVISION OF FP/RH SERVICES TO WORKERS THROUGH MOHP MOBILE CLINICS}

In recent years, MOHP had offered $\mathrm{FP} / \mathrm{RH}$ services to factory workers through mobile clinics that were dispatched by the health directorate in each governorate and sent to some private factories in coordination with factory management. Voluntary services offered included medical examinations, counseling, and free FP methods for those who chose to use a method. Mobile clinics did not constitute a significant financial, administrative, or technical burden on the factory, but they came with certain drawbacks. Anecdotal reports from female factory staff indicate that some beneficiaries were reluctant to frequent mobile clinics, mainly due to the lack of privacy, especially when the caravan was parked in a visible location where male workers may be present. Another issue that has been previously documented in Egypt is that mobile clinics do not come to the factory on a fixed schedule and do not have the same staff each time (Salah-Eldeen and Al-Attar 2009) leading to problems with follow-up, method resupply, and management of side effects. Such issues could be resolved through better communication and coordination between health directorates and factory management.

\section{PROVISION OF FP COUNSELING BY THE FACTORY NURSE AND REFERRAL TO A NEARBY FP/RH FACILITY FOR SERVICES}

Egypt's Labor Law No. 12 of 2003 stipulates that a factory with 50 workers or more should have a venue for providing health services on its premises. Thus, most factories have infirmaries that offer basic first aid services that are staffed with a part-time physician and a full-time nurse. Offering FP/RH counseling by the factory nurse could be a valuable addition that meets the needs of factory workers. Workers who need additional $\mathrm{FP} / \mathrm{RH}$ services could be referred to external private or public sector providers. This is the model that the Youth Health Project (YHP) employed in garment factories in Port Said as described in Box 1.

This model can meet workers' FP/RH needs by providing adequate information and counseling and linking them with trained health care providers for services. However, it was found that workers who resided in neighboring governorates were not able to access the network of trained private providers, as they had to catch the factory bus back to their governorates immediately after work. Additionally, some workers found prices of services offered by the linked private doctors to be too expensive (Essam et al. 2021).

\section{ON-SITE PROVISION OF FP/RH SERVICES}

On-site provision of FP/RH services capitalizes on the existing factory infirmary or clinic and integrates $\mathrm{FP} / \mathrm{RH}$ into services already offered by the clinic. Female factory workers interviewed as part of the YHP indicated that they prefer seeking FP/RH services at their workplace so they would not use their leave time or lose any monetary incentives for taking time off to visit the clinic. This model allows workers to benefit from the proximity of an on-site clinic and the expertise of clinic staff. Additionally, it gives workers access to quality $\mathrm{FP} / \mathrm{RH}$ services in the workplace at a reasonable cost while promoting continuity of care.

However, offering FP services at the factory clinic poses some risks to workers' privacy as well as a burden on factory management as they need to procure FP commodities and/or train factory doctors and nurses in the provision of FP services. An alternative model is a clinic established to service factory workers employed at multiple factories and managed by an independent entity (e.g., nongovernmental organization [NGO]). In the case of the YHP in Port Said, the clinic was owned by the Investors' Association and managed by Port Fouad Association as described below.

The remainder of this brief provides practical steps and recommendations to business owners, factory managers, factory health committees, and service providers in factories in providing voluntary, affordable, high-quality, on-site FP/RH services to factory workers. The brief is based on lessons learned from the implementation of the U. S. Agency for International Development (USAID)-funded YHP in the Port Said governorate (Essam et al. 2021). YHP was implemented by the Evidence project in eight garment factories in the Investment Zone in Port Said (more on the intervention in Port Said is provided in Box 1). The brief also draws on international and local evidence as well as insights from project staff, beneficiaries, service providers, and factory managers. 


\section{BOX 1: YOUTH HEALTH PROJECT IN PORT SAID}

The Evidence Project, with support from USAID/Egypt and in collaboration with a local NGO, Port Fouad Childhood and Motherhood Association (PFCMA), implemented a project that aimed at increasing demand for FP/RH services among young male and female factory workers in Port Said, Egypt. The project intervention targeted male and female garment factory workers aged 18-35 in eight factories in Port Said's Free Investment Zone.

A total of 300 young male and female factory workers in the eight project factories were trained as peer educators to communicate health messages to their colleagues through faceto-face communication, social and behavior change communication materials, and social media. Throughout the project, peer educators have disseminated messages to nearly 24,000 workers in all eight factories. In addition, factory nurses were

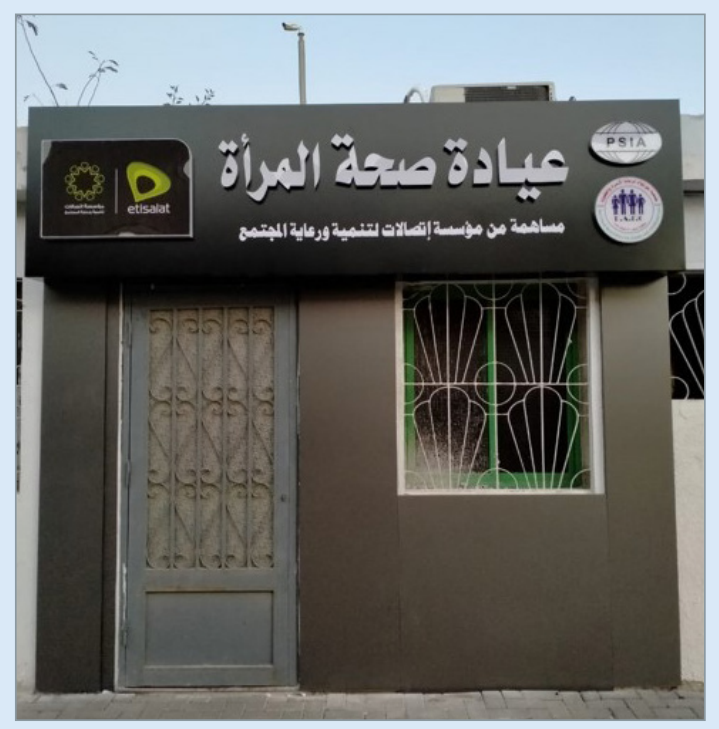
trained to offer FP/RH counseling and to refer factory workers seeking FP services to private providers outside of the factory setting. The private providers were also trained by YHP. A total of 35 factory nurses, 277 pharmacists, and 64 private physicians were trained in FP/RH counseling and/or service provision.

The project facilitated the establishment of a Women's Health Clinic (WHC) in the Investment Zone of Port Said with support from PFCMA, the Investors' Association in Port Said, and Etisalat Foundation. The clinic will serve nearly 20,000 female workers in the Investment Zone.

In an effort to ensure the sustainability of the intervention, the project established a health committee $(\mathrm{HC})$ in each factory to manage factory worker health programs, including the integration of FP/RH services. The HC is composed of 7-10 members, representing male and female workers, managers, health care providers, and other staff in the factory.

\section{RECOMMENDATIONS FOR ON-SITE PROVISION OF FP/RH SERVICES}

Following are recommendations for providing on-site $\mathrm{FP} / \mathrm{RH}$ services either through the factory infirmary or through a standalone clinic.

\section{CLINIC BENEFICIARIES}

The factory clinic may offer $\mathrm{FP} / \mathrm{RH}$ services to both female and male workers. If the clinic is to offer services to both male and female workers, different hours should be set for each gender to ensure privacy. Earlier research in Egypt has shown that women do not seek $\mathrm{FP} / \mathrm{RH}$ services from clinics that also serve male clients (Said 2012).

\section{SERVICES TO BE OFFERED AT THE CLINIC}

At a minimum, the clinic may offer FP/RH counseling and provision of FP methods. Other medical services like antenatal care may also be offered based on workers' needs and availability of resources.

\section{Counseling}

The provision of FP methods should be accompanied with FP counseling. A factory nurse and/or physician could be trained to offer FP/RH counseling to factory workers. ${ }^{i}$ Counseling could address concerns and misconceptions about specific FP methods and help workers make informed decisions about FP. Visual aids and social and behavior change communication materials such as flyers and flipcharts should be made available

'Curricula for training physicians and nurses produced under the Evidence Project could be found here: https://evidenceproject.popcouncil. org/resource/fp-rh-training-curriculum-egypt/ 
to assist the clinic doctor and nurse in counseling factory workers.

\section{Family planning methods}

With appropriate training of providers, various FP/ $\mathrm{RH}$ methods may be offered in the factory clinic, such as intrauterine devices (IUDs), combined pills, progestin-only pills, combined injectables, progestin-only injectables, and condoms. These services can only be offered by a physician, since MOHP only allows physicians to insert/remove IUDs, and prescribe pills and injectables. On the other hand, the nurse can resupply beneficiaries with pills, injectables, and condoms. Subdermal implants may not be offered in the factory clinic as they are only offered in select MOHP FP centers, and their insertion and removal require providers to have additional training. Referral for implants and other FP methods not available onsite should also be offered to ensure that factory workers are presented with a range of FP methods to select from. The factory clinic may receive subsidized FP commodities from the Family Planning Sector of MOHP after obtaining appropriate licensing and codes. The clinic may also buy contraceptive methods or receive donations from pharmaceutical companies

\section{Other medical services}

The clinic may offer essential antenatal care (ANC) services such as monitoring pregnant workers' weight and blood pressure and offering them information on selfcare and nutrition during pregnancy and answering their questions about pregnancy or childbirth. External health care providers may be invited to offer additional health services on a regular or ad hoc basis. These services could include premarital counseling, management of menstrual problems, breast cancer screening, infertility, and management of reproductive tract infections and/or sexually transmitted infections.

\section{CLINIC LOCATION}

If an already established factory clinic will offer $\mathrm{FP} / \mathrm{RH}$ services, it is vital to ensure that workers have adequate privacy to receive $\mathrm{FP} / \mathrm{RH}$ counseling and services. The factory could assign hours everyday or dedicate certain days for female workers and other hours or days for male workers.

If a stand-alone clinic will be established specifically to offer FP/RH services, it is important for it to be located in an easy to reach site with large signs or arrows indicating the path to the clinic. This site should also ensure client privacy. While it is preferable to be easy to reach, the site should also be far enough away from the main workplace where workers might linger.

\section{CLINIC LAYOUT}

Since the clinic is likely to be visited by several workers at the same time, it is recommended to designate a waiting area that is both comfortable and private. The counseling and exam areas should be separated by partitions, and both should ensure complete visual and auditory privacy. A sign that has the name of the clinic should be visible to allow workers to locate the clinic. Another sign should show clinic working hours, name(s) of service provider(s), and services offered at the clinic along with the price of each service.

\section{CLIENT FLOW AND CLINIC WORK HOURS}

Due to the nature of work in a factory setting, workers as well as factory managers may have concerns regarding disruption of the production process if workers seek $\mathrm{FP} / \mathrm{RH}$ services in the factory clinic during work hours. Several managers involved in the YHP suggested setting up an appointment system to avoid crowding at the clinic and disruption of production.

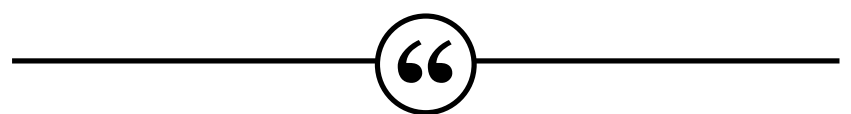

If a worker needs something urgently, then she can go during the workday and the supervisor would understand, I'm sure. If not, then she can go during her break time. -Female worker, 39 years old, with 3 children

In addition, it might be helpful to have a mobile phone or land line at the clinic to allow workers to call and book an appointment to prevent crowding at the clinic and save workers' time. The mobile phone could also be used to allow service providers to offer teleconsultations if necessary (e.g., in times of pandemics such as COVID-19).

Several female workers indicated that they would prefer the clinic work hours to extend one hour before or after factory work hours. This would allow workers who 
are unable to use the clinic during their short break time to receive services without affecting their work schedule.

\section{6}

If I need a FP/RH service urgently, I will definitely get some sort of permission and go to the clinic during the day. By the time

I'm done with work, it (clinic) might be closed. If I'm sure the clinic will be open before or after work, I would go then. That way I will be more comfortable. I would finish my work and then get a service the way I want.

-Female worker, 32 years old, with 1 child

\section{PRIVACY AND CONFIDENTIALITY}

Timely and affordable FP/RH services should be delivered in a way that ensures that women are making informed, voluntary decisions about FP and that their autonomy, privacy, and confidentiality are fully protected.

Privacy and confidentiality may be difficult to maintain in a factory setting where workers know each other and where workers may be seen by their co-workers while visiting the clinic. The above challenges could be overcome by setting up an appointment system, so workers would not overlap at the clinic. Clinic staff should be trained on procedures for protecting workers' privacy and confidentiality of data and should be instructed not to share client data with their coworkers or supervisors.

\section{PRICING OF SERVICES}

To ensure continuity and sustainability of high-quality service provision in the clinic, it is crucial that the clinic covers its own operating costs and that no financial burden is added to the factory's finances. Therefore, it is necessary to set a price range for services to make them affordable to the workers. It is advisable to conduct a small survey to find out how much workers are willing to pay for various services. According to female factory workers in Port Said, the prices of services offered by the clinic should be comparable to those offered by local NGOs. The prices in Table 1 were proposed by interviewed workers.

\section{TABLE 1 SUGGESTED PRICES FOR FP/RH SERVICES OFFERED AT THE FACTORY CLINIC}

\begin{tabular}{|ll|}
\hline Service & Price $^{*}$ \\
Gynecological examination & 30 EGP \\
Ultrasound & 30 EGP \\
IUP insertion & 80 EGP \\
Copper IUD & \\
3-month injectables (Depo-provera) & 1 EGP \\
Monthly injectable (Mesocept) & 2 EGP \\
Combined pills (Microgenest) & 0.65 EGP \\
Oral contraceptive pills (Levonor) & 1 EGP \\
Vaginal suppositories (NoGravida) & 1 piece: 0. 25 EGP \\
& 6 pieces: 1.50 EGP \\
Condoms & 0.10 EGP \\
Implanon & 5 EGP \\
Emergency contraception (Contraplan 2) & 2 EGP \\
\hline
\end{tabular}

*1 USD is equivalent to $15.64 \mathrm{EGP}$

${ }^{\dagger} \mathrm{NB}$ : Those methods are offered to the clinic at a subsidized price by MOHP.

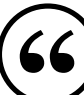

If prices are closer to those of NGOs, a lot of women will prefer this.

-Female worker, 39 years old, with 3 children

\section{BASIC EQUIPMENT AND SUPPLIES}

A factory clinic is generally equipped to provide first aid to workers. The clinic will likely have basic equipment and supplies such as an examination table, a desk and chairs, a medicine cupboard, disinfectant, sphygmomanometer, stethoscope, and some medication such as analgesics, antipyretics, gauze, cotton, and antiseptics for wounds.

In order for the clinic to offer FP/RH services, it must be equipped with some essential medical devices and supplies according to the guidelines for providing FP/ 


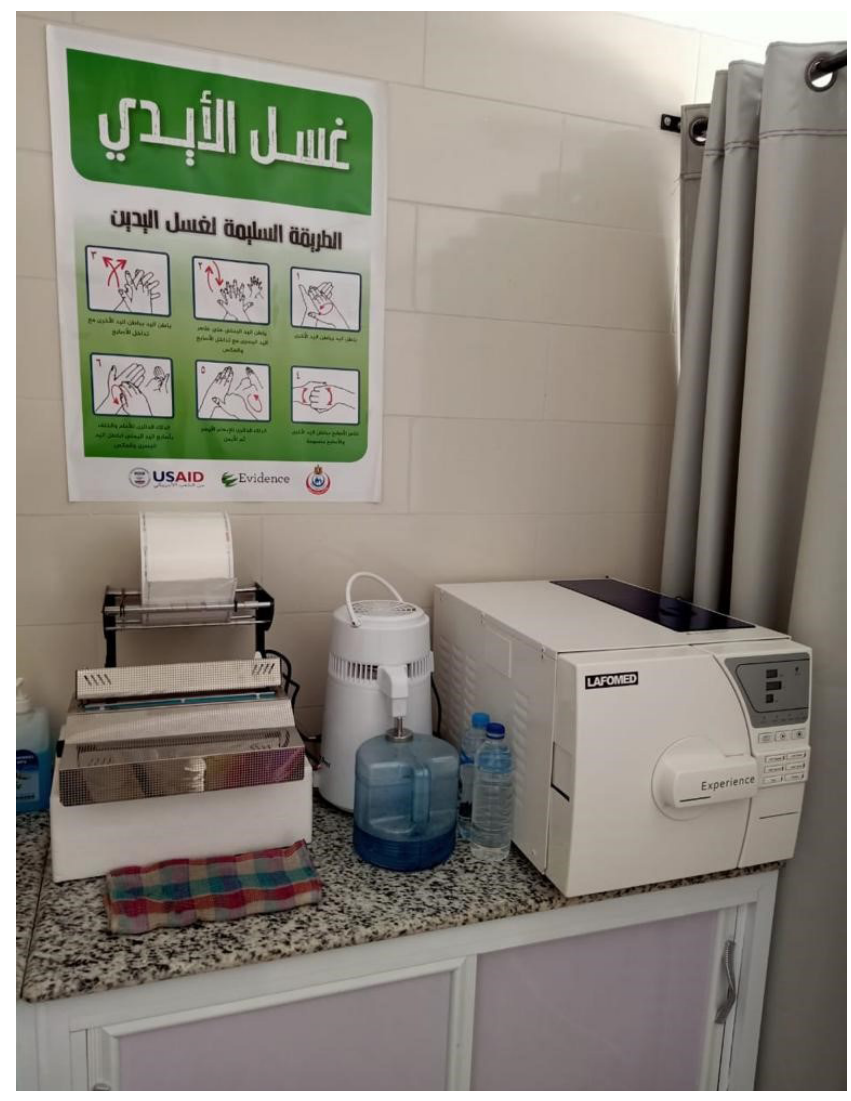

RH services established by the World Health Organization (WHO). These devices and supplies include equipment used in gynecology examinations as well as inserting/removing IUDs, such as ovum forceps, speculum, sound, vulsellum, and autoclave. Additionally, auxiliary devices to ensure quality service provision should be made available, such as a scale for measuring weight and height for women seeking antenatal care. Although an ultrasound machine may not be essential for FP services, MOHP recommends conducting ultrasound imaging before and after IUD insertion. The presence of an ultrasound machine may be also essential if the clinic were to offer ANC and gynecological services. A list of equipment and supplies that were provided by the YHP in setting up the WHC in Port Said is provided in Table 2. The WHC was equipped using both MOHP and WHO guidelines. The cost of setting up the clinic was covered through a donation from Etisalat Foundation while space was donated by Port Said Investors' Association. The Evidence Project provided technical assistance to Port Fouad Childhood and Motherhood Association (PFCMA) in setting up and managing the clinic. In settings where there is a large number of factories, equipment costs and supplies could be shared by various factor owners.
TABLE 2 LIST OF ESSENTIAL EQUIPMENT FOR A FACTORY FP/RH CLINIC

\begin{tabular}{|ll|}
\hline Item & Number \\
\hline Examination bed & 1 \\
Examination chair & 1 \\
Searchlight & 1 \\
Two stainless steel containers & 1 \\
Sphygmomanometer & 2 \\
Stethoscope & 2 \\
Thermometer & 5 \\
Scale for measuring weight and height & 1 \\
Casco & 10 \\
Vulsellum & 3 \\
Sound & 3 \\
Handling forceps & 1 \\
Ovum forceps & 4 \\
Scissors & 4 \\
Crocodile & 2 \\
Small container & 1 \\
Latex gloves & 3 \\
Medical gauze & 1 \\
Cotton & 1 \\
Safety box & $1 \mathrm{~kg}$ \\
Heavy duty gloves & 25 \\
Betadine (200ml) & 2 \\
Gel for ultrasound & 2 \\
Rolls for sterilization $(15 \mathrm{~cm}-200 \mathrm{~m})$ & 1 \\
Machine for rolls for sterilization & 1 \\
Container for the instruments & 1 \\
Towel & 1 \\
Sheets & 1 \\
Drum (small) & 4 \\
Drum (big) & 1 \\
Autoclave & 1 \\
Ultrasound machine & 1 \\
\hline
\end{tabular}

Notes: a) Equipment list is based on the guidelines provided by WHO (*https://www.who.int/medical_devices/md_maternal_v12_web.pdf) b) This list was used to furnish the Women's Health Clinic in the Investment Zone in Port Said.

\section{CLINIC MANAGEMENT AND STAFFING}

In Port Said, the YHP partnered with PFCMA and the Investor's Association in establishing the WHC in the Investment Zone. Partnering with a civil society organization facilitated the licensing procedures for the establishment of the clinic and took the burden of 
managing the clinic away from the factories. The WHC team in Port Said is composed of a physician, a nurse, and a clinic manager. The WHC is managed by the Investment Zone's HC which is composed of 1-2 HC members from each factory. The $\mathrm{HC}$ in each factory is mainly concerned with addressing the health needs of workers.

\section{Physician}

A part-time Obstetrician/Gynecologist (Ob/Gyn) or a general practitioner could be hired to offer FP/RH services. That physician must be trained in the provision of $\mathrm{FP} / \mathrm{RH}$ services according to MOHP guidelines. It might be preferable to have a female doctor offer FP/ $\mathrm{RH}$ to female workers if feasible. The YHP hired a fulltime female Ob/Gyn to offer FP/RH in the WHC.

The physician would be responsible for the technical management of the clinic, the provision of health services and follow-up and supervision of the nurse's work. The physician would offer counseling, conduct physical exams, and offer FP methods including IUD insertion. Additionally, the physician may refer workers who need higher-level services, e.g., high-risk pregnancies, to contracted specialists.

\section{Nurse}

The clinic needs to have a full-time nurse who is trained in the provision of FP counseling. The clinic nurse would be responsible for counseling and helping clients make informed choices about FP methods. Additionally, the nurse would be responsible for maintaining equipment and devices, restocking FP methods, and maintaining standards for infection control and waste disposal. Setting appointments and keeping case files are also responsibilities of the nurse.

\section{Administrative manager}

The administrative manager would be responsible for following-up on the work of clinic staff and services offered, providing supplies needed for the clinic, dealing with external parties to purchase supplies/equipment or to refer clients to external hospitals or clinics, as well as submitting periodic reports to the HC. The administrative manager monitors and evaluates the provision of services at the clinic. This can be done by setting a mechanism in place to solicit feedback from clinic users as well as $\mathrm{HC}$ members. The $\mathrm{HC}$ is responsible for monitoring and evaluation of the quality of services offered by the clinic as well as ensuring the sustainability of worker health programs. The $\mathrm{HC}$ should also measure client satisfaction with the services offered and take corrective measures as needed. The clinic could also connect to MOHP Health Management Information System and hence MOHP could track quality of its services and monitor disbursement of FP commodities.

\section{CONCLUSION}

The availability and provision of $\mathrm{FP} / \mathrm{RH}$ information and high-quality services in factories have the potential to affect a large number of young people, especially those who are about to start a family. This strategic approach is in line with the National Population Strategy (National Population Council 2014), which focuses on offering FP. There are multiple models for integrating $\mathrm{FP} / \mathrm{RH}$ services in factories that are good for both workers and employers. Choosing the most appropriate model depends on the conditions of each factory and varies according to industry, number of workers, and their needs.

\section{REFERENCES}

Abdel-Tawab, Nahla et al. 2020. “Fertility preferences and behaviors among younger cohorts in Egypt: trends, correlates, and prospects for change," Research report. Washington, DC: Population Council, The Evidence Project

Central Agency for Public Mobilization and Statistics. 2017. Egypt Census 2017. Cairo: CAPMAS. Accessed December 16, 2020 http://www. capmas.gov.eg/Pages/ShowPDF.aspx?page_id=/Admin/Pages\%20Files/ 201710914947book.pdf

Essam, Maryam, Nahla Abdel-Tawab, Elizabeth Tobey, and Aparna Jain. 2021. "Meeting family planning needs of factory workers in Port Said: Lessons from pilot testing an intervention in eight garment factories," Policy Brief. Washington DC: Population Council, The Evidence Project

National Population Council. (2014). National Population Strategy (20152030). In Arabic. Cairo, National Population Council.

Roudi-Fahimi, F. and S. El Feki. 2011. "Facts of life: Youth sexuality and reproductive health in the Middle East and North Africa." Washington, DC: Population Reference Bureau. Accessed December 16, 2020. https://www. prb.org/wp-content/uploads/2011/07/facts-of-life-youth-in-middle-east.pdf

Said, Madiha. 2012. "Reasons for shift from IUD to oral contraceptives among MOHP clients (2007-2012)." Cairo: Ministry of Health and Population and UNFPA.

Salah-Eideen, G. and T. S. Al-Attar. 2009. “10 years after introducing mobile clinics in Assuit, Egypt.” Population Reference Bureau. 


\section{ACKNOWLEDGMENTS}

We are grateful to the individuals and organizations that made this brief possible. Special thanks go to Etisalat Foundation, the Investors' Association in Port Said, and Port Fouad Childhood and Motherhood Association for their support in setting up the Women's Health Clinic. The continued support of the factory managers in the Port Said Investment Zone during the implementation of this project is deeply acknowledged. The contributions of Tarek Alam Eldin, Population Council Field Operations and Legal Manager, in setting up and managing the clinic are highly appreciated. Last but not least, we wish to thank factory workers, managers, and service providers who openly shared their views and insights about providing family planning services in factory settings.

THE EVIDENCE PROJECT

Population Council 4301 Connecticut Ave, NW, Suite 280 Washington, DC 20008 evidenceproject@popcouncil.org

(c) 2021 The Population Council, Inc

Photos: Port Fouad Childhood and Motherhood Association (PFCMA)
USAID

The Evidence Project is made possible by the generous support of the American people through the United States Agency for International Development (USAID) under the terms of cooperative agreement no. AIDOAA-A-13-00087. The contents of this document are the sole responsibility of the Evidence Project and Population Council and do not necessarily reflect the views of USAID or the United States Government.

\section{Evidence}

The Evidence Project uses implementation science-the strategic generation, translation, and use of evidence-to strengthen and scale up family planning and reproductive health programs to reduce unintended pregnancies worldwide. The Evidence Project is led by the Population Council.

Suggested Citation: Salama, Nesrine, Maryam Essam, Nahla Abdel-Tawab, Elizabeth Tobey. 2021. "Providing family planning and reproductive health services in factory settings: Lessons from Port Said, Egypt," Research Brief. Washington, DC: Population Council, The Evidence Project. 